\title{
Patterns of smoking, risk factors for smoking, and smoking cessation among Vietnamese men in Massachusetts (United States)
}

\author{
John M Wiecha, Vanna Lee, Jane Hodgkins
}

\begin{abstract}
Objectives-To measure the prevalence and patterns of, and risk factors for, smoking and other tobacco use among Vietnamese men in Massachusetts (United States).

Methods-Data were obtained via a telephone interview of 774 Vietnamese men in 1994.

Design-Cross-sectional survey administered via telephone in 1994.

Setting-Massachusetts, United States.

Subjects-Randomly selected Vietnamese men (n = 774).

Main outcome measures-Present and past use of tobacco products, knowledge and attitudes regarding tobacco, and risk factors for tobacco use. Results were compared with data from the Massachusetts general population.

Results-Vietnamese men smoked at a rate 1.9 times that of the Massachusetts general men's rate $(43 \%$ vs $24 \%)$. The smoking rate did not decrease with increasing length of residence in the United States. In a logistic regression, risk factors for current smoking were: age in the thirties; history of parental smoking; lower educational level; higher depression score; low level of exercise; lack of health insurance; and geographical origin from the south coast of Vietnam. Smoking cessation declined with increasing depression score. Most smokers $(76 \%)$ had no plans to quit smoking.

Conclusions-Vietnamese men smoke at much higher rates than the general population, and are much less likely to be planning cessation. High rates of depression and sociocultural barriers to smoking cessation must be addressed in efforts to reduce tobacco use among this high-risk population.
\end{abstract}

(Tobacco Control 1998;7:27-34)

Department of Family and Community Medicine, University of Massachusetts Medical School, Worcester, Massachusetts, USA.

Correspondence to: J M Wiecha, Department of Family Medicine, Dowling 5 South, Boston Medical Center 1 Medica Center Place, Boston,

02118 , USA

John.Wiecha@bmc.org
Keywords: smoking cessation, tobacco use, Vietnamese

\section{Introduction}

Southeast Asian Americans are a rapidly growing minority in the United States. Since 1975 more than a million refugees and immigrants have emigrated from southeast Asia to the United States. ${ }^{1}$ Over a half $(59 \%)$ of southeast Asians who have come to this country originated from Vietnam. ${ }^{1}$ The Vietnamese population in the United States increased by more than twofold between 1980 and 1990, ${ }^{2}$ and is projected to reach four million by the year $2030 .^{3}$

Southeast Asians have a high prevalence of chronic disease risk factors, including cigarette smoking. The smoking rate among men in Vietnam (73\%) is the highest in Asia, ${ }^{4}$ and lung cancer is the most common cancer among Vietnamese men. ${ }^{5}$ Several studies on patterns of cigarette smoking have been done in the southwest and midwest United States. Estimates of the prevalence of smoking among Vietnamese men range from $35 \%$ to $57 \%$ with far lower rates among women. ${ }^{6-8}$ The extent of the smoking problem among Vietnamese and other southeast Asian men in the United States has prompted the Public Health Service to designate southeast Asian men as a high-risk group. $^{9}$

Despite the rapid growth of this minority population, there have been few studies on its tobacco use, and those done to date have been limited to populations in western regions of the United States. Prior studies suggest that regional variation in smoking patterns exists among Vietnamese American men. ${ }^{10}$ In addition, there has been little research on smoking risk factors for southeast Asians, such as depression, ${ }^{11}$ which is prevalent among southeast Asian immigrants and refugees, ${ }^{12-14}$ and which may be an important factor in any tobacco control strategy for this population.

Little is known about stages of readiness for smoking cessation, or about patterns of cessation attempts among southeast Asian Americans. The efficacious design of tobacco control strategies for this population is hampered by the relative absence of information.

The purpose of this study was to measure the prevalence and patterns of tobacco use among Vietnamese men in a previously unstudied geographical region of the United States (Massachusetts), and to identify their smoking risk factors and readiness to quit smoking. Massachusetts has a sizable Vietnamese population, is a state that has a commitment to tobacco control through the Massachusetts Tobacco Control Program, and is the location of the southeast Asian Health Program, the sponsor of this research project. A prior study reported high smoking rates among Vietnamese youth in Massachusetts. ${ }^{15}$

\section{Methods}

SUBJECTS

According to the 1990 census, ${ }^{16}$ Massachusetts had a population of 15449 Vietnamese, of 
Table 1 Characteristics of male Vietnamese respondents to the Tobacco Use Survey, Massachusetts, 1994

\begin{tabular}{|c|c|c|c|c|}
\hline Characteristic & $n$ & $\%$ of total & Smokers (\%) & $p$ \\
\hline \multicolumn{5}{|l|}{ Age (years) } \\
\hline $18-29$ & 224 & 28.9 & 37.2 & \multirow[t]{5}{*}{0.001} \\
\hline $30-39$ & 211 & 27.3 & 55.5 & \\
\hline $40-49$ & 178 & 23.0 & 42.7 & \\
\hline $50-59$ & 109 & 14.1 & 35.8 & \\
\hline$\geqslant 60$ & 52 & 6.7 & 36.5 & \\
\hline \multicolumn{5}{|c|}{ Time in United States (years) } \\
\hline$<1$ & 45 & 5.8 & 42.2 & \multirow[t]{5}{*}{0.5} \\
\hline $1-2$ & 157 & 20.3 & 38.5 & \\
\hline $3-5$ & 152 & 19.6 & 46.1 & \\
\hline $6-10$ & 161 & 20.8 & 47.8 & \\
\hline$>10$ & 259 & 33.5 & 41.7 & \\
\hline \multicolumn{5}{|l|}{ Part of Vietnam raised in } \\
\hline North central & 36 & 4.7 & 36.1 & \multirow[t]{5}{*}{0.001} \\
\hline North coastal & 20 & 2.6 & 30.0 & \\
\hline South central & 468 & 60.8 & 42.8 & \\
\hline South coastal & 121 & 15.7 & 59.5 & \\
\hline Middle & 125 & 16.2 & 34.3 & \\
\hline \multicolumn{5}{|l|}{ Father's smoking status } \\
\hline Ever smoked & 355 & 50.2 & 49.0 & \multirow[t]{2}{*}{$<0.01$} \\
\hline Never smoked & 352 & 49.8 & 38.9 & \\
\hline \multicolumn{5}{|l|}{ Mother's smoking status } \\
\hline Ever smoked & 41 & 5.6 & 48.9 & \multirow[t]{2}{*}{0.52} \\
\hline Never smoked & 695 & 94.4 & 43.6 & \\
\hline \multicolumn{5}{|l|}{ English spoken } \\
\hline Very well & 33 & 4.3 & 24.2 & \multirow[t]{4}{*}{0.01} \\
\hline Well & 281 & 36.4 & 38.4 & \\
\hline Not well & 409 & 52.9 & 47.6 & \\
\hline Not at all & 50 & 6.5 & 48.0 & \\
\hline \multicolumn{5}{|l|}{ Educational achievement } \\
\hline Less than 9th grade & 153 & 20.2 & 59.9 & \multirow[t]{6}{*}{$<0.001$} \\
\hline Some high school & 164 & 21.6 & 41.5 & \\
\hline Graduated high school & 201 & 26.5 & 43.3 & \\
\hline Some college & 136 & 17.9 & 37.5 & \\
\hline BA level degree & 76 & 10.0 & 31.6 & \\
\hline Above BA level degree & 28 & 3.7 & 14.3 & \\
\hline \multicolumn{5}{|l|}{ Health insurance } \\
\hline Medicaid & 229 & 30.8 & 44.7 & \multirow[t]{5}{*}{$<0.01$} \\
\hline Medicare & 9 & 1.2 & 44.4 & \\
\hline Private & 281 & 37.8 & 39.5 & \\
\hline Other & 98 & 13.2 & 32.3 & \\
\hline None & 126 & 17.0 & 56.4 & \\
\hline \multicolumn{5}{|c|}{ Depression score $(4=$ no symptoms $)$} \\
\hline 4 & 342 & 44.3 & 38.1 & \multirow[t]{4}{*}{0.001} \\
\hline $5-6$ & 258 & 33.4 & 42.6 & \\
\hline 7 & 79 & 10.2 & 48.1 & \\
\hline$\geqslant 8$ & 93 & 12.0 & 59.1 & \\
\hline \multicolumn{5}{|l|}{ Escaped from Vietnam } \\
\hline Yes & 481 & 62.8 & 47.4 & \multirow[t]{2}{*}{0.003} \\
\hline No & 285 & 37.2 & 36.5 & \\
\hline Exercised in past 30 days & & & & \\
\hline Yes & 369 & 47.8 & 34.7 & $<0.001$ \\
\hline No & 403 & 52.2 & 50.9 & \\
\hline
\end{tabular}

whom $5580(36.1 \%)$ were men aged 18 or older. The median age of Vietnamese men in Massachusetts in 1990 was 31.9 years. ${ }^{17}$

Data on Vietnamese men in Massachusetts was collected for this study via a telephone administered survey. In the 1990 census, $96.8 \%$ of Vietnamese households reported a telephone in their house or apartment. ${ }^{18}$ A total of $85 \%$ of Vietnamese have one of 12 family names. ${ }^{19}$ These names, plus additional less common Vietnamese names, were included in a search list. Phone numbers of persons with one of these names were obtained by manual abstraction of 1994 NYNEX directories. This methodology has been used extensively for sampling Vietnamese in prior studies. ${ }^{8} 102021$

The directories abstracted represent the 12 communities with the largest Vietnamese populations, ${ }^{2}$ with the exception of Brockton (ranked 12th) for which a 1994 directory was unavailable. Cambridge (ranked 16th) was also included in the sample because of its contiguity with Boston. As a group, these communities represented $4174(74.8 \%)$ of the Massachusetts Vietnamese adult male population. ${ }^{2}$

A 50\% random sample of these numbers was called by one of three trained, bilingual interviewers from April through August, 1994. Adult Vietnamese male residents of the households were enumerated and one randomly selected using a Kish table procedure. ${ }^{22} \mathrm{~A}$ maximum of 10 telephone call attempts were made on various days of the week and times of day to each selected individual.

MEASURES

Questions on tobacco use were adapted from the Massachusetts Tobacco Survey, a statewide study completed in $1994 . .^{23}$ Those who had smoked at least 100 cigarettes and who had smoked any part of a cigarette in the past 30 days were defined as a current smoker. A former smoker had smoked at least 100 cigarettes in the past and was not currently a smoker. Self-reported smoking status in a sample of Vietnamese men in Ohio correlated well with saliva cotinine validation, ${ }^{24}$ indicating that self-reported smoking in this population is an adequate smoking status measure.

Readiness to attempt smoking cessation was measured using the stage-of-change constructs (precontemplation, contemplation, preparation) as indicated by whether the smoker had no plans to quit smoking, planned to quit within the next six months, or planned to quit smoking within a month. ${ }^{25}$ These measures are useful predictors of subsequent cessation attempts and success. ${ }^{26}$

Acculturation was approximated by reporting how well English is spoken; language use is a reasonable indicator of acculturation level in southeast Asian and other populations. ${ }^{27-29}$

The Hopkins symptom checklist is a validated Vietnamese-language screening instrument for anxiety and depression, ${ }^{30}$ and four items from the 15-item depression scale were included (frequency of: (a) feeling low in energy, slowed down; (b) difficulty falling asleep, staying asleep; (c) worrying about things; (d) feeling "blue"). Compared with the structured clinical interview of the American Psychiatric Association's Diagnostic and statistical manual (revised third edition), these items perform well individually as screens for depression among Vietnamese with sensitivities ranging from $65 \%$ to $96 \%$ and specificities from $81 \%$ to $93 \%$ (oral personal communication, $M$ Smith-Fauzi, Harvard School of Public Health, Department of Epidemiology, July 1996). Respondents scaled how often each of these feelings had bothered them in the past week, ranked on a four-point scale from "not at all" to "extremely". The scores for the four items were summed, yielding a possible score ranging from 4 (no symptoms) to 16 (all four symptoms were extremely bothersome over the past week). Because the entire depression scale was not included in the survey, we did not 
Table 2 Smoking behaviour among Vietnamese men, Massachusetts, 1994

\begin{tabular}{|c|c|c|}
\hline Measure & $n$ & $(\%)$ \\
\hline \multicolumn{3}{|l|}{ Among all respondents $(n=774)$} \\
\hline Smoked in the past month & 334 & 43.2 \\
\hline Smoked daily in the past month & 296 & 38.3 \\
\hline Smoked some days, not in the past month & 1 & 0.1 \\
\hline Quit smoking cigarettes & 161 & 20.8 \\
\hline Never smoked cigarettes & 277 & 35.8 \\
\hline \multicolumn{3}{|l|}{ Among current smokers $(n=334)$} \\
\hline \multicolumn{3}{|l|}{ Age started smoking on a regular basis (years) } \\
\hline$\leqslant 10$ & 5 & 1.5 \\
\hline $11-15$ & 35 & 10.5 \\
\hline $16-20$ & 195 & 58.4 \\
\hline $21-25$ & 57 & 17.1 \\
\hline$>25$ & 42 & 12.6 \\
\hline \multicolumn{3}{|l|}{ Since started smoking regularly, cessation for } \\
\hline$\geqslant 1$ years & 43 & 12.9 \\
\hline \multicolumn{3}{|l|}{ Cigarettes smoked per day } \\
\hline$<10$ & 151 & 45.2 \\
\hline $11-15$ & 101 & 30.2 \\
\hline $16-20$ & 65 & 19.5 \\
\hline$>20$ & 17 & 5.1 \\
\hline \multicolumn{3}{|l|}{$\begin{array}{l}\text { Time from awakening to smoking first cigarette } \\
\text { (minutes) }\end{array}$} \\
\hline$<16$ & 89 & 28.3 \\
\hline $16-30$ & 76 & 24.2 \\
\hline $31-60$ & 44 & 14.0 \\
\hline$>60$ & 105 & 33.4 \\
\hline \multicolumn{3}{|l|}{ Social patterns of smoking } \\
\hline Mainly with others & 121 & 36.2 \\
\hline Mainly alone & 90 & 26.9 \\
\hline Equally alone and with others & 123 & 36.8 \\
\hline \multicolumn{3}{|l|}{ Cigarettes usually purchased } \\
\hline By the pack & 214 & 64.7 \\
\hline By the carton & 112 & 33.8 \\
\hline Never buy & 5 & 1.5 \\
\hline \multicolumn{3}{|l|}{ Brand preference } \\
\hline Marlboro & 240 & 75.5 \\
\hline Newport & 17 & 5.3 \\
\hline 555 & 30 & 9.4 \\
\hline Other brand & 31 & 9.8 \\
\hline \multicolumn{3}{|l|}{ Perceived difficulty to quit cigarettes } \\
\hline Very & 114 & 34.1 \\
\hline Somewhat & 78 & 23.4 \\
\hline Not & 117 & 35.0 \\
\hline Don't know & 25 & 7.5 \\
\hline Any serious cessation attempt in the past & 154 & 51.0 \\
\hline \multicolumn{3}{|c|}{ Number of serious cessation attempts: in Vietnam } \\
\hline 0 & 259 & 86.6 \\
\hline 1 & 22 & 7.4 \\
\hline$\geqslant 2$ & 18 & 6.0 \\
\hline \multicolumn{3}{|l|}{ Number of serious cessation attempts: in USA } \\
\hline 0 & 166 & 55.3 \\
\hline 1 & 64 & 21.3 \\
\hline$\geqslant 2$ & 70 & 23.3 \\
\hline $\begin{array}{l}\text { Received health professional advice during } \\
\text { cessation attempt in USA }\end{array}$ & 29 & 21.3 \\
\hline $\begin{array}{l}\text { Use of health education materials during la } \\
\text { cessation attempt in USA }\end{array}$ & 8 & 5.9 \\
\hline \multicolumn{3}{|l|}{ Recent quitters (past 5 years): where quit } \\
\hline USA & 94 & 87.9 \\
\hline Vietnam & 11 & 10.3 \\
\hline Other & 2 & 1.9 \\
\hline
\end{tabular}

correlate smoking behaviour with a diagnosis of depression; instead a continuous scale was used for analysis under the assumption that risk of smoking would correlate with depressive symptoms over a continuum of depressive symptoms as has been reported previously. ${ }^{11}$

At each level of depression score, smoking prevalence and the quit ratio were calculated. The quit ratio, a commonly used indicator of smoking cessation, is the percentage of ever- smokers who had quit (former smokers/eversmokers) $\times 100 .^{31}$

Additional items, including motivation for smoking cessation and health knowledge items, were adapted from the National Health Interview Survey. ${ }^{32}$ Most attitude and belief items were translated from the Massachusetts Tobacco Survey. ${ }^{23}$ Several additional items about purported benefits of smoking were created after a series of extended interviews with Vietnamese men. Attitude and belief measures, particularly negative attitudes and beliefs about smoking, were included because they have been shown to correlate with stage of change in smoking cessation. ${ }^{23}{ }^{25}$ The survey was translated and back-translated. Completion required an average of 21 minutes.

\section{ANALYSIS}

Univariate and bivariate analyses were completed using sas statistical software. Logistic regressions were run on EGRET software. ${ }^{33}$ We used $\chi^{2}$ analysis for the trend (Mantel extension) test ${ }^{34}$ to test the statistical significance of the relationship between levels of depression score and smoking prevalence and between levels of depression score and the quit ratio.

A logistic regression model was developed for predictors of current smoking by including in the model, independent variables significant at the $\mathrm{p}=0.05$ level in the univariate analyses. Variables in the model with a significance level of more than 0.05 were subsequently eliminated sequentially.

\section{Results}

RESPONSE RATE

Calls were made to 1630 households. Nearly a quarter $(23.7 \%)$ of households reported no Vietnamese men inhabitants; $10.7 \%$ were wrong numbers; $8.9 \%$ refused to be enumerated, $7.4 \%$ of identified respondents could not be reached after 10 calls, and $1.8 \%$ were not completed for other reasons. A total of 1039 men were identified as eligible for the survey. Of this number, $774(74.5 \%)$ were successfully interviewed.

\section{POPULATION CHARACTERISTICS}

The median age of respondents was 37.0 years. Respondents under 40 years old comprised $56.2 \%$ of the sample, and $26.1 \%$ had arrived during the past two years (table 1) Over a half $(60.6 \%)$ were married, $29.5 \%$ had been incarcerated in a prison camp, and $37.5 \%$ had served in the military. The unemployment rate was $39.7 \%$ and many had no health insurance or were receiving Medicaid benefits. Religious affiliation was reported as Catholic by $28.0 \%$ of men, Buddhist by $38.4 \%$, and ancestor worship by $16.7 \%$. Income was reported by $70 \%$ of respondents, among whom $20.2 \%$ had a household income of less than $\$ 10000$.

Among subjects who reported having a regular physician, 218 (38.9\%) had a physician who was able to speak Vietnamese. Of the 328 respondents who spoke English not well or not at all, and who had a regular doctor, 169 $(51.5 \%)$ had a physician who either spoke no 
Table 3 Knowledge and attitudes about smoking: smokers vs non-smoking Vietnamese men, Massachusetts, 1994

\begin{tabular}{llcr}
\hline Characteristic & $\begin{array}{l}\text { Non-smokers agreed } n \\
(\%)\end{array}$ & \multicolumn{1}{l}{$\begin{array}{l}\text { Smokers agreed } \\
n(\%)\end{array}$} & $p$ \\
\hline Smoking helps you/people look more attractive & $35(9.0)$ & $44(14.0)$ & 0.04 \\
Smoking helps you/people look more masculine & $49(12.5)$ & $58(18.0)$ & 0.04 \\
Smoking helps you/people look more mature & $67(17.5)$ & $75(23.7)$ & 0.04 \\
Smoking makes you/people smell bad & $407(95.1)$ & $253(77.6)$ & $<0.001$ \\
Smoking makes the/your teeth yellow & $399(96.8)$ & $273(83.2)$ & $<0.001$ \\
Smoking helps the average smoker/you concentrate & $142(47.2)$ & $294(94.5)$ & $<0.001$ \\
Smoking is harmful to people's/your health & $416(99.1)$ & $281(87.5)$ & $<0.001$ \\
Smoking is addictive & $388(95.6)$ & $5(1.6)$ & $<0.001$ \\
Smoking has some health benefits & $4(1.0)$ & $218(67.3)$ & 0.5 \\
Smoking helps people keep warm in a cold climate & $169(55.2)$ & $106(33.9)$ & 0.002 \\
Smoking low tar cigarettes reduces health risks & $106(25.0)$ & $154(71.0)$ & 0.009 \\
Smoking is bad for the heart & $229(81.5)$ & $282(94.3)$ & 0.006 \\
Smoking cessation now would improve future health & $393(97.5)$ & $220(69.0)$ & 0.03 \\
Smoking upsets your family (smokers only) & NA & $199(66.3)$ & NA \\
Smoking at parties helps you relax (smokers only) & NA & $285(85.6)$ & NA \\
Smoking harms the health of kids who are exposed & $400(91.1)$ & & 0.02 \\
\hline
\end{tabular}

NA $=$ not applicable.

Vietnamese or had no translator available. More than half of the subjects reported some distress from symptoms of depression in the past week.

\section{TOBACCO USE}

Smoking prevalence among Vietnamese men in Massachusetts was $43.2 \%$ (table 2 ) Most of these men were daily smokers. The mean number of cigarettes smoked daily was 11.1, with a median of 10.0. Five cigarettes or fewer per day were smoked by $111(33.2 \%)$ of smokers. The mean age when smoking began regularly was 19.6 years. Half of the smokers had their first cigarettes soon after awakening. The cigarette brand overwhelmingly preferred was Marlboro, and $85(26.6 \%)$ reported smoking "light" cigarettes. Sixty-three per cent of smokers believed they were addicted; these people smoked more cigarettes than those who indicated they were not addicted (mean of 13.3 vs 7.3 cigarettes per day, $\mathrm{p}<0.001$ ).

A number of factors were associated with smoking (table 1). Those who gave or received cigarettes as gifts were more likely to be smokers than were subjects who did not do so $(52.5 \%$ vs $41.9 \%, p=0.045)$. Smoking was not associated with marital status, income, employment, history of incarceration, military duty, or religious affiliation. One subject reported having tried smokeless tobacco. A pipe or cigar was used daily by three $(0.4 \%)$, and some days by $20(2.7 \%)$ respondents.

One hundred and one $(13.1 \%)$ men had given or received cigarettes as gifts, and 74 $(20.3 \%)$ subjects reported that as children it was a practice in their household to light their

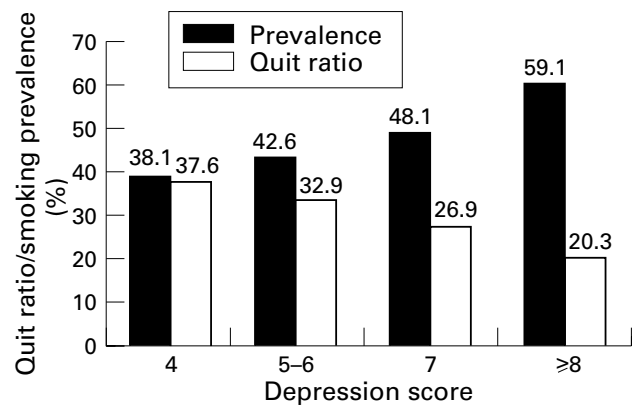

Figure 1 Smoking prevalence and quit ratio according to depression score, Vietnamese men, Massachusetts, 1994. father's cigarettes. Of this group, $56.8 \%$ lit the cigarettes in their own mouths and then handed the cigarette to their father.

\section{KNOWLEDGE AND ATTITUDES}

Smokers were significantly more likely to attribute positive attributes to smoking, including beliefs that smoking helps one look more attractive, more masculine, and more mature; helps concentration; and helps one to keep warm in a cold climate (table 3) Smokers were significantly less likely to respond that smoking makes one smell bad, makes the teeth yellow, is harmful to the health, is addictive, is bad for the heart, or harms the health of exposed children. Most smokers (69.0\%) reported that smoking upset their family. Among smokers, $42.5 \%$ believed that it was worthwhile to seek a physician's help when trying to quit smoking.

Light smokers (five or fewer cigarettes daily) were compared with heavier smokers. Half $(48.6 \%)$ of light smokers reported smoking mainly with other people, vs $30.0 \%$ of heavier smokers $(\mathrm{p}<0.001)$. A third $(36.4 \%)$ of light smokers considered themselves addicted vs $75.8 \%$ of heavier smokers, $(\mathrm{p}<0.001)$, and light smokers were less likely to report that it would be very hard to quit smoking than were heavier smokers $(20.7 \%$ vs $40.8 \%, \mathrm{p}<0.001)$. Among subjects who reported income, there was no correlation between income and number of cigarettes smoked per day.

\section{DEPRESSION}

Depression score varied by smoking status, with current smokers having the highest mean score (5.6), significantly higher than that among former smokers (5.1) or among men who never smoked (5.2) $\quad(\mathrm{p}<0.01$ for both comparisons). There was a strong correlation between depression score and smoking prevalence (figure 1) ( $\mathrm{p}$ for trend $<0.001$ ). In addition, as depression level increased, the quit ratio decreased linearly ( $p$ for trend $=0.005$ ) (figure 1).

\section{MULTIVARIATE ANALYSIS}

Seven factors were identified as independently associated with current smoking (table 4) After adjustment for education, English language 


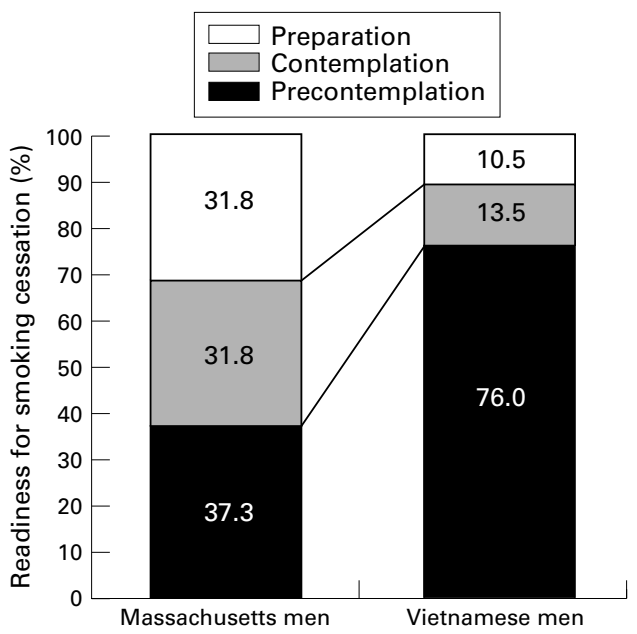

Figure 2 Readiness for smoking cessation, Vietnamese men vs all men, Massachusetts, 1994.

proficiency was no longer a significant predictor of smoking.

SMOKING CESSATION

Half of current smokers reported no prior cessation attempts (table 2) Those who had tried to quit smoking in the past were much more likely to have tried since arriving in the United States than in Vietnam.

The most common reasons given for attempting cessation in the past were: concern about future health $(21.3 \%)$; pressure from family or friends (14.4\%); cost $(13.5 \%)$; concern about present health $(12.6 \%)$ or a current health problem $(12.0 \%)$; loss of desire to smoke $(12.5 \%)$; and concern about effect of smoking on children (11.3\%). Approximately $8 \%$ reported attempting cessation to help gain entry into the United States. Among those stating that a health problem motivated their cessation attempt, the most common condition mentioned was cough $(50.0 \%)$.

Most current smokers who recently attempted cessation did not use any health education materials, and had not received advice from a health professional (table 2) Among subjects who had quit smoking in the past five years, nicotine replacement was used by five $(5.3 \%)$, and none had used traditional Chinese medical practices or medicines when they had successfully quit.

Table 4 Independent predictors of current smoking among Vietnamese men: Massachusetts, 1994. Results of logistic regression

\begin{tabular}{llll}
\hline Characteristic & OR & $95 \% C I$ & $p$ \\
\hline Age (years) & & & \\
$\quad 18-29$ & 1.0 & & \\
$30-39$ & 1.9 & $1.2-2.9$ & 0.005 \\
$40-49$ & 1.2 & $0.7-1.8$ & 0.53 \\
$\quad$ E50 & 0.9 & $0.5-1.4$ & 0.50 \\
Either parent smoked & 1.4 & $1.0-2.0$ & 0.037 \\
Higher educational level & 0.8 & $0.7-0.9$ & $<0.001$ \\
From south coast of Vietnam & 1.9 & $1.2-3.0$ & 0.005 \\
Higher depression score† & 1.3 & $1.1-1.5$ & 0.003 \\
No exercise in past 30 days & 1.6 & $1.1-2.2$ & 0.011 \\
No health insurance & 1.6 & $1.0-2.4$ & 0.045 \\
& & & \\
\end{tabular}

$\star$ Scaled with six levels: $0=$ less than 9 th grade; $5=$ above BA level degree.

†Scaled with four levels of depression score: 0 (no symptoms) to 3 (depression score of $\geqslant 8$ ); see text and table 1 .

$\mathrm{OR}=$ odds ratio, $\mathrm{CI}=$ confidence interval.
Several factors distinguished men who had attempted to quit smoking from those who had not. Subjects with at least one serious cessation attempt in the USA were more likely than those persons with none to be from the south coast of Vietnam $(26.9 \%$ vs $16.3 \%, \mathrm{p}=0.02)$; to report planning to quit smoking within the next six months $(42.5 \%$ vs $10.8 \%, \mathrm{p}<0.01)$; to report that their family was upset with their smoking $(78.4 \%$ vs $69.2 \%, \mathrm{p}<0.01)$, and to respond that quitting smoking would be very hard $(45.3 \%$ vs $29.9 \%, \mathrm{p}<0.01)$. There were no other significant differences between these two groups among factors shown in tables 1 or 3 , and no difference in depression score or number of cigarettes smoked per day between the two groups.

Two hundred and one $(60.9 \%)$ smokers saw a physician in the 12 months preceding the survey. Of this group, $54.0 \%$ of the physicians reportedly discussed smoking with the respondent, $49.0 \%$ advised cessation, $2.7 \%$ suggested choosing a quit date, and $4.3 \%$ prescribed medication to help with cessation. Of those advised to quit smoking by their doctor, $22.7 \%$ reported making a cessation attempt. Among current smokers, 166 (49.7\%) reported seeing a dentist in the 12 months before the survey. Forty-three $(26.1 \%)$ of the dentists reportedly discussed smoking and $21.2 \%$ advised cessation. Forty-six $(15.1 \%)$ of smokers reported buying fewer cigarettes after cigarettes prices rose due to a state cigarette tax increase of 25 cents per pack in January 1993.

Stage of readiness for smoking cessation among smokers is presented in figure 2. Data for the Massachusetts general population are presented for comparison. Vietnamese men were far less likely than the general population to have any future intention to quit smoking, and a third as likely to be in the preparation stage of smoking cessation.

Comparison of factors from tables 1 and 3 between precontemplators and those preparing to quit revealed significant differences in several factors. Precontemplators were less likely to report that their family was upset with their smoking (58.6\%) than were smokers with plans to quit $(88.8 \%)(\mathrm{p}<0.001)$. Precontemplators were less educated than preparers ( $47.8 \%$ vs $61.3 \%$ with more than a high school education, $p=0.04$ ); were less likely to have made a serious past cessation attempt in the United States $(34.2 \%$ vs $76.0 \%, \mathrm{p}<0.001)$; were less likely to report that quitting would be very hard $(33.3 \%$ vs $48.0 \%, \mathrm{p}=0.02)$; and were less likely to report having heard of the disease cancer $(78.8 \%$ vs $97.5 \%, \mathrm{p}=0.01)$. Adjusting for educational level did not significantly alter the association between having heard of cancer and precontemplation status. There was no difference in numbers of cigarettes smoked per day between the two groups, and no difference in depression score.

\section{MEDIA EXPOSURE}

Vietnamese-language media of any content was reported available in a magazine or newspaper by $356(66.8 \%)$ of men; on television by 220 (41.3\%); and on radio by 
three $(0.6 \%)$. Three persons reported having received free cigarette samples by cigarette company representatives, and $23(4.3 \%)$ had received free promotional clothing from a cigarette company.

\section{Discussion}

The smoking rate among Vietnamese men in this study was similar to the high rates measured among Vietnamese living in the western United States. Within Massachusetts, the proportion of Vietnamese men who were smokers was higher than that among any other racial or ethnic subgroup including white men (24\%), Hispanics (20\%), blacks (22\%), or a group termed "Asians" (19\%). ${ }^{23}$ Vietnamese men were 1.9 times more likely to smoke than were men statewide.

These findings demonstrate that considerable heterogeneity exists with regard to tobacco use within the Asian population, and that misleading results can be produced by not disaggregating specific ethnic subgroups from the larger "Asian" grouping. A recent study by one of the authors showed that among older boys in a school-based sample, the highest smoking rate was observed among Vietnamese $(37.7 \%) .^{15}$

The mean number of cigarettes smoked daily among Vietnamese men (11), was much lower that among men in the Massachusetts general population (22), ${ }^{23}$ but comparable with other minorities in Massachusetts, ${ }^{23}$ and to Vietnamese living in California ${ }^{8}$ and Vietnam. ${ }^{4}$

A significant proportion of our sample smoked only a few cigarettes per day. Such persons have been termed "chippers", or light smokers, who are at lower risk of developing dependence. ${ }^{35}$ It has been speculated that chippers' stimulation for smoking could be the presence of others smoking. ${ }^{36}$ The finding that the light smokers in this study were more likely to report smoking with others than were heavier smokers, and were much less likely to report being addicted, suggests that these patterns also apply to Vietnamese men. However, because light smokers were as unlikely to report plans to quit in the next six months as were heavier smokers, cessation efforts should not neglect this subset of smokers.

Adjustment for confounding among multiple smoking risk factors using a regression model identified a number of independent risk factors for smoking. These included a higher depression score, lack of health insurance, age in the thirties, parental smoking, less education, less exercise, and geographical area of origin in Vietnam.

Depression has been shown to be associated with smoking in adults ${ }^{11}$ and teenagers. ${ }^{37}$ The most common interpretation of this association is that depression promotes or has a causal role in the use of tobacco, ${ }^{11}$ or that tobacco improves the dysphoric mood of depressed persons. ${ }^{38}$ People with depression are also less likely to quit smoking. ${ }^{11}$ Depression is extremely common among Vietnamese and other refugees and immigrants from southeast Asia; prevalence estimates vary from $5.5 \%$ to more than $50 \%$ depending on the sample and screening instrument. ${ }^{12-14}$ Mental health disorders need to be recognised as significant factors in individual and population-based efforts to reduce smoking among Vietnamese.

The smoking rate varies by age among Vietnamese males living in Vietnam, with the highest rates among men aged 25-44 years. We found a similar pattern in Massachusetts, with the highest rate $(55.5 \%)$ among men in their thirties. This association was also observed among Vietnamese men in California. ${ }^{39}$

Those with no health insurance had a significantly elevated smoking rate, an association which did not appear to be strongly confounded by socioeconomic status, as measured by the proxy of educational level. Consequently, individuals who lack health insurance are at particular risk of smoking morbidity due to higher smoking rates, and will experience more barriers to accessing the healthcare system to obtain smoking cessation services.

Our findings show a very strong association between smoking and educational level, with rates varying from $14 \%$ among men with the highest educational attainment to $60 \%$ among those with less than nine years of education. A similar association was observed among Vietnamese in Vietnam ${ }^{4}$ and California. ${ }^{39}$

In studies done among English-speaking populations, parental smoking is not a powerful predictor of smoking initiation, and whatever influence does exist appears to be strongest among whites and females. ${ }^{40}$ However, our results show that smoking by a parent confers a substantial risk for smoking later in life among Vietnamese men.

Unlike prior samples of Vietnamese men which showed a decrease in smoking rate with increasing length of residency in the United States, ${ }^{81039}$ we did not find an association with this proxy measure of acculturation. Although ability to speak English, another acculturation proxy, was strongly related to smoking in the univariate analysis, it was confounded by educational level and did not remain an independent predictor of smoking. It is possible that there are distinct attributes, such as lower unemployment rates, of Vietnamese populations in other parts of the country that render those populations more susceptible than Massachusetts Vietnamese to the smoking norms of the general population. The gradual decline in smoking rates among Vietnamese observed in California and Texas may not be a universal phenomenon among southeast Asian populations in all parts of the country.

Respondents reporting origins from the south coastal region of Vietnam had substantially higher smoking rates than did those from other parts of the country, a finding that was not strongly confounded by other risk factors. This region is rural and supports fishing and farming activities. A similar regional variation exists within Vietnam, with the highest smoking prevalence among people living in rural areas. ${ }^{4}$ The finding of so few smokers in the preparation stage of smoking cessation is important. Prior work has suggested that moving smokers through the stages of precontemplation to contemplation and ultimately to 
smoking cessation can be accomplished by applying stage-specific, individualised self-help materials. ${ }^{41}$ Further work is needed to ascertain the applicability of these methods to southeast Asian smokers.

In prior studies, smokers who are preparing to quit have been shown to smoke less than those with no such plans, ${ }^{23}{ }^{25}$ and are more likely to have made prior cessation attempts. ${ }^{23}$ The relationship between stage of change and number of cigarettes smoked daily was not observed in our study, possibly due to the relatively small variation in daily cigarette consumption and the resultant diminished ability to discriminate on the basis of this variable. Family disapproval was significantly associated with past quit attempts and plans to quit within the next six months, suggesting that engaging the family in cessation efforts may be particularly influential for Vietnamese men.

A meta-analysis of randomised clinical trials of nicotine replacement has demonstrated the effectiveness of this therapy in helping smokers to quit. ${ }^{42}$ Efforts at reducing smoking rates among Vietnamese and other southeast Asians should include provision of smoking cessation services to smokers ready to quit.

The efficacy of community-based smoking cessation programmes for Vietnamese has been demonstrated in mass-media and patient-centred approaches. The southeast Asian Health Program used a programme of community outreach and patient-centred counselling with transdermal nicotine patch therapy. At a mean follow-up interval of 7.4 months, $44 \%$ of smokers had maintained abstinence, and those who were still smoking had significantly reduced their daily cigarette consumption. ${ }^{43}$ In addition, an anti-tobacco campaign in San Francisco, California evaluated prospectively significantly reduced the odds of being a smoker. ${ }^{21}$

Several limitations of this study should be noted. The sampling frame was based on subjects living in households with listed telephones. Measures could be biased because respondents were older than the Vietnamese population enumerated in the 1990 census. There may also be systematic differences in smoking patterns or risk factors among subjects with and without listed telephones. A potentially more valid sampling scheme would involve household enumeration and random household sampling. However, we are somewhat reassured by census data indicating that most Vietnamese households reported having a telephone.

The depression measures used are likely to have been relatively imprecise measures of depression. Given that these relatively crude measures were likely to have misclassified persons without regard to their smoking status (that is, random misclassification) had we included the entire Hopkins symptom checklist in this survey, an even stronger association between smoking and depression might have been observed. ${ }^{44}$

It is interesting and relevant to health policy planners and tobacco control professionals that several differences were observed between
Vietnamese smokers in California and Massachusetts. Unlike California, the smoking rate in Massachusetts did not drop with longer residence in the United States. This stability in smoking rates may also exist among Vietnamese and other southeast Asians living in other areas of the country. Because there is no apparent temporal trend reducing smoking rates among Vietnamese in Massachusetts and probably other states, intervention will be required to achieve health goals. ${ }^{9}$

These efforts will require a multidisciplinary approach including prevention efforts for young people and women, as well as research, development, and dissemination of linguistically and culturally appropriate mass-media and health education materials. Strategies for addressing depression in tobacco control efforts need to be a focus of research. Interventions should target smokers in the precontemplation stage, who comprise a large majority of smokers in this population. Healthcare provider education strategies and intervention strategies need to be developed to motivate and facilitate smoking cessation counselling in the clinical setting. Finally, community-based agencies that serve southeast Asian populations must be supported to develop outreach strategies to provide tobacco control programmes, including group and individual cessation counselling, and well as nicotine replacement therapy, without regard to health insurance status.

This research was supported by the Massachusetts Department of Public Health, Tobacco Control Program, Contract SCDPH29005048H71. The authors gratefully acknowledge the editorial assistance of Dr Judith Ockene.

1 Office of Refugee Resettlement, US Department of Health and Human Services. Refugee resettlement program. Report to Congress, 31 January 1993.

2 US Bureau of the Census, Commerce Department. 1990 Census of population and housing. Summary, tape file 3 (STF-3). Washington, DC: Bureau of the Census, 1991.

3 Bouvier LF, Agresta AS. The future Asian population in the United States. In: Fawcett JT, Carino BV, eds. Pacific bridges: the new immigration from Asia and the Pacific Islands. bridges: the new immigration from Asia and the Pacific Islands. 1987.

4 Institute of Sociology. Vietnam: a tobacco epidemic in the making. A tobacco use prevalence survey and analysis of the economic barriers to tobacco control. Hanoi, Vietnam: National Centre for Human and Social Sciences, 1995.

5 Pham THA, Parkin DM, Nguyen TH, et al. Cancer in the population of Hanoi, Vietnam, 1988-1990. Br F Cancer 1993;68:1236-42.

6 US Centers for Disease Control and Prevention. Behavioral risk factor survey of Vietnamese-California, 1991. MMWR 1992;41:69-72

7 US Centers for Disease Control and Prevention. Cigarette smoking among Chinese, Vietnamese, and HispanicsCalifornia, 1989-1991. MMWR 1992;41:362-7.

8 Jenkins CNH, McPhee SJ, Bird JA, et al. Cancer risks among Vietnamese refugees. West $\mathcal{F}$ Med 1990;153:34-9.

9 US Department of Health and Human Services. Healthy people 2000. Washington, DC: US Government Printing Office, 1990.

10 Jenkins CNH, McPhee SJ, Bird JA, et al. Regional variation in smoking prevalence among Vietnamese-American men. Abstract, annual meeting of the American Public Health Association. Washington, DC: APHA, 1992.

11 Anda RF, Williamson DF, Escobedo LG, et al. Depression and the dynamics of smoking. $\mathcal{F} A M A$ 1990;264:1541-5.

2 Lin EH, Ihle LJ, Tazuma L. Depression among Vietnamese refugees in a primary care clinic. Am f Med 1985;78:41-4.

13 Buchwald D, Manson S, Dinges NG, et al. Prevalence of depressive symptoms among established Vietnamese refugees in the United States: detection in a primary care setting. $\mathcal{F}$ Gen Int Med 1993;9:76-81.

14 Hinton LW, Chen Y-CJ, Nang D, et al. DSM-III-R disorders in Vietnamese refugees. If Nerv Ment Dis 1993;181:113-22.

15 Wiecha JM. Differences in patterns of tobacco use in Vietnamese, African-American, Hispanic, and Caucasian adolescents in Worcester, MA. Am f Prev Med 1996; 12:29-37. 
16 US Bureau of the Census, Commerce Department. 1990 Census of population and housing, general population characteristics, Massact

17 US Bureau of the Census, Commerce Department. 1990 Census of population and housing. Summary tape file 2 (STF-2), table PB5, characteristic iteration 014 (Vietnamese). Washington, DC: Bureau of the Census, 1991

18 US Bureau of the Census, Commerce Department. Public use micro data sample A, 1990 census of population and housing. Washington, DC: Bureau of the Census, 1991.

19 Huard P, Durand M. Viet-nam, civilization and culture. Ecole Française d'Extrème-Orient. Imprimerie Nationale, 1990.

20 Jenkins C, McPhee SJ, Ngoc-The H, et al. Cigarette smoking among Vietnamese immigrants in California. Am $\mathcal{f}$ Health Promotion 1995;9:254-6.

21 Jenkins CNH, McPhee SJ, Le A, et al. Effectiveness of a media-led intervention to reduce smoking prevalence
among Vietnamese. Am $\mathcal{A}$ Public Health 1997;87:1031-4.

22 Kish L. Survey sampling. New York: John Wiley and Sons, 1965:396-401.

23 Biener L, Fowler FJ, Roman AM. Results of the 1993 Massachusetts Tobacco Survey: tobacco use and attitudes at the start of the Massachusetts Tobacco Control Program. Boston: Massachusetts Department of Public Health, 1994

24 Wewers ME, Dhatt RK, Moeschberger ML, et al. Misclassification of smoking status among Southeast Asian adult immigrants. Am f Respir Crit Care Med 1995;152:191721.

25 Fava Jl, Velicer WF, Prochaska JO. Applying the transtheoretical model to a representative sample of smokers. Addict Behav 1995;20:189-203

26 Prochaska JO, DiClemente CC, Norcross JC. In search of how people change. Applications to addictive behavior. Am Psychol 1992;47:1102-114.

27 Marin G, Sabogal F, Marin BV, et al. Development of a short acculturation scale for Hispanics. Hisp $\mathcal{f}$ Behav Sci 1987;9:183-205.

28 Deyo RA, Diehl AK, Hazuda $\mathrm{H}$, et al. A simple language-based acculturation scale for Mexicanlanguage-based acculturation scale for MexicanAmericans: validation and application to

29 Anderson J, Moeschberger M, Chen MS, et al. An acculturation scale for Southeast Asians. Soc Psychiatry Psychiatric Epidemiol 1993;28:134-41.

30 Hinton WL, Du N, Chen YC, et al. Screening for major depression in Vietnamese refugees: a validation and comparison of two instruments in a health screening population. f Gen Int Med 1994;9:202-6.
31 Pierce JP, Fiore MC, Novotny TE, et al. Trends in cigarette smoking in the United States: educational differences are increasing. F $A M A$ 1989;261:56-60.

32 US Department of Health and Human Services. National Health Interview Survey. Atlanta, Georgia: Public Health Service, Centers for Disease Control and Prevention, National Center for Health Statistics, 1987.

33 EGRET software, version 0.25.6. Statistics and Epidemiology Research Corporation, Seattle, Washington.

34 Schlesselman JJ. Case control studies design, conduct and analysis. New York: Oxford University Press, 1982:203-6.

35 Shiffman S, Fischer LB, Zettler-Segal M, et al. Nicotine exposure among non dependent smokers. Arch Gen Psychiatry 1990;47:333-6.

36 Ockene JK, Chiriboga DE, Zevallos JC. Smoking in Ecuador: prevalence, knowledge, and attitudes. Tobacco Control 1996;5:1-6.

37 Patton GC, Hibbert M, Rosier MJ, et al. Is smoking associated with depression and anxiety in teenagers? Am f Public Health 1996;86:225-30.

38 Gilbert DG. Why people smoke: stress-reduction, coping enhancement, and nicotine. Recent Adv Tobacco Sci 1994;20:107.

39 McPhee SJ, Jenkins C, Wong C, et al. Smoking cessation intervention among Vietnamese Americans: a controlled trial. Tobacco Control 1995;4(suppl 1):S16-24.

40 US Department of Health and Human Services. Preventing tobacco use among young people. A report of the Surgeon General, 1994. Atlanta, Georgia: Public Health Service, Centers for Disease Control and Prevention, Office on Smoking and Health, 1994 (US Government Printing Office No S/N 017-001-00491-0.)

41 Prochaska JO, DiClemente CC, Velicer WF, et al. Standardized, individualized, interactive, and personalized self-help ized, individualized, interactive, and personalized self-help programs for

42 Fiore MC, Smith SS, Jorenby DE, et al. The effectiveness of the nicotine patch for smoking cessation. A metaanalysis. fAMA 1994;271:1940-7.

43 Wiecha JM, Lee V, Ngo T, et al. Smoking cessation counselling in Southeast Asian refugees and immigrants: results at 6-month follow-up. Abstract, annual meeting of the American Public Health Association. Washington, DC: APHA, 1995.

44 Friedman GD. Primer of epidemiology, 4th ed. New York: McGraw-Hill, 1994. 